\title{
Sex differences in electrolyte imbalances caused by SARS-CoV-2: a case-control study
}

\author{
Arianna Pani ${ }^{1}$, Elvira Inglese ${ }^{2}$, Massimo Puoti $^{2}$, Valeria Cento $^{1}$, Claudia Alteri ${ }^{1}$, \\ Alessandra Romandini ${ }^{1}$, Federica Di Ruscio ${ }^{2}$, Michele Senatore $^{1}$, Mauro Moreno ${ }^{2}$, Paolo \\ Tarsia $^{2}$, Fabrizio Colombo ${ }^{2}$, Oscar Epis ${ }^{2}$, Valentina Panetta ${ }^{3}$, Chiara Vismara ${ }^{2}$, Andrea \\ Bellone $^{2}$, and Francesco Scaglione ${ }^{1}$ \\ ${ }^{1}$ Università degli Studi di Milano \\ ${ }^{2}$ Niguarda Hospital \\ ${ }^{3}$ L'altrastatistica srl - Consultancy \& Training
}

March 27, 2021

\begin{abstract}
Background - Since SARS-CoV-2 spread, evidences regarding sex differences in progression and prognosis of COVID-19 have emerged. Besides this, studies on patients' clinical characteristics have described electrolyte imbalances as one of the recurrent features of COVID-19. Methods - We performed a case-control study on all patients admitted to the emergency department (ED) from 1st March to 31st May 2020 who had undergone a blood gas analysis and a nasopharyngeal swab test for SARSCoV-2 by rtPCR. We defined positive patients as cases and negatives as controls. The study was approved by the local ethics committee Area 3 Milan. Data were automatically extracted from the hospital laboratory SQL-based repository in anonymized form. We considered as outcomes potassium $(\mathrm{K}+)$, sodium $(\mathrm{Na}+)$, chlorine $(\mathrm{Cl}-)$ and calcium $(\mathrm{Ca}++)$ as continuous and as categorical variables, in their relation with age, sex and SARS-CoV-2 infection status. Results - We observed a higher prevalence of hypokalemia among patients positive for SARS-CoV-2 (13.7\% vs $6 \%$ of negative subjects). Positive patients had a higher probability to be admitted to the ED with hypokalemia (OR 2.75, 95\% CI 1.8-4.1 p <0.0001) and women were twice as likely to be affected than men (OR 2.43, 95\% CI 1.67-3.54 p<0.001). Odds ratios for positive patients to manifest with an alteration in serum $\mathrm{Na}+$ was (OR 1.6, 95\% CI 1.17-2.35 p<0.001) and serum chlorine (OR 1.6, 95\% CI 1.03-2.69 p<0.001). Notably, OR for positive patients to be hypocalcemic was $7.2(95 \%$ IC $4.8-10.6 \mathrm{p}<0.0001)$ with a low probability for women to be hypocalcemic (OR 0.63, 95\% IC 0.4-0.8 p=0.005). Conclusions - SARS-CoV-2 infection is associated with a higher prevalence of hypokalemia, hypocalcemia, hypochloremia and sodium alterations. Hypokalemia is more frequent among women and hypocalcemia among men.
\end{abstract}

Sex differences in electrolyte imbalances caused by SARS-CoV-2: a case-control study Arianna Pani, MD*1, Elvira Inglese*2, Massimo Puoti, MD3, Valeria Cento, MD. PhD1, Claudia Alteri, PhD1, Alessandra Romandini ${ }^{1}$, MD1, Federica Di Ruscio, MD2, Michele Senatore ${ }^{1}$, MD, Mauro Moreno, MD4, Paolo Tarsia, MD5, Fabrizio Colombo, MD6, Oscar Massimiliano Epis, MD7, Valentina Panetta8, Chiara Vismara ${ }^{2}$, Andrea Bellone, MD9 and Francesco Scaglione, MD, PhD1,2 *These two authors equally contributed 1Department of Oncology and HematoOncology, University of Milan, Milan, Italy; E-mail: arianna.pani@unimi.it; E-mail: valeria.cento@unimi.it; E-mail: claudia.alteri@unimi.it; E-mail: alessandra.romandini@unimi.it Email: michele.senatore@unimi.it2SC Clinical Chemistry and Microbiology, ASST Grande Ospedale Metropolitano Niguarda, Milan, Italy; E-mail: elvira.inglese@ospedaleniguarda.it; E-mail: federica.diruscio@unimi.it; Email:chiara.vismara@ospedaleniguarda.it; E-mail:_francesco.scaglione@unimi.it3Infectious Diseases Unit, ASST Grande Ospedale Metropolitano Niguarda, Milan, Italy;E-mail: mas- 
simo.puoti@ospedaleniguarda.it4Healthcare Management Department, ASST Grande Ospedale Metropolitano Niguarda, Milan, Italy; E-mail: mauro.moreno@ospedaleniguarda.it5Pneumology Unit, ASST Grande Ospedale Metropolitano Niguarda, Milan, Italy; E-mail: paolo.tarsia@ospedaleniguarda.it6Internal Medicine Department, ASST Grande Ospedale Metropolitano Niguarda, Milan, Italy;E-mail: fabrizio.colombo@ospedaleniguarda.it7Rheumatology Unit, ASST Grande Ospedale Metropolitano Niguarda, Milan, Italy; E-mail: oscar.epis@ospedaleniguarda.it8Biostatistics office, L'altrastatistica srl -Consultancy \& Training, Rome, Italy 9Emergency Department, ASST Grande Ospedale Metropolitano Niguarda, Milan, Italy;E-mail: andrea.bellone@ospedaleniguarda.it

\section{Corresponding author}

Arianna Pani

Assistant Professor of Pharmacology

Assistant Director of the Postgraduate School of Clinical Pharmacology and Toxicology

Department of Oncology and Hemato-Oncology

University of Milan

Mailing address:

Department of Oncology and Onco - Hematology, Italy

e-mail- arianna.pani@unimi.it

Phone: $++39-0250316950$

Fax: $++39-0250317050$

ABSTRACTBackground - Since SARS-CoV-2 spread, evidence regarding sex differences in progression and prognosis of COVID-19 have emerged. Besides this, studies on patients' clinical characteristics have described electrolyte imbalances as one of the recurrent features of COVID-19.Methods - We performed a case-control study on all patients admitted to the emergency department (ED) from 1st March to 31st May 2020 who had undergone a blood gas analysis and a nasopharyngeal swab test for SARS-CoV-2 by rtPCR. We defined positive patients as cases and negatives as controls. The study was approved by the local ethics committee Area 3 Milan. Data were automatically extracted from the hospital laboratory SQLbased repository in anonymized form. We considered as outcomes potassium $(\mathrm{K}+)$, sodium $(\mathrm{Na}+)$, chlorine $(\mathrm{Cl}-)$ and calcium $(\mathrm{Ca}++)$ as continuous and as categorical variables, in their relation with age, sex and SARS-CoV-2 infection status.Results - We observed a higher prevalence of hypokalemia among patients positive for SARS-CoV-2 (13.7\% vs $6 \%$ of negative subjects). Positive patients had a higher probability to be admitted to the ED with hypokalemia (OR 2.75, 95\% CI 1.8-4.1 $\mathrm{p}<0.0001$ ) and women were twice as likely to be affected than men (OR 2.43, 95\% CI 1.67-3.54 p<0.001). Odds ratios for positive patients to manifest with an alteration in serum $\mathrm{Na}+$ was (OR 1.6, 95\% CI 1.17-2.35 p <0.001) and serum chlorine (OR 1.6, 95\% CI 1.03-2.69 $\mathrm{p}<0.001$ ). Notably, OR for positive patients to be hypocalcemic was 7.2 (95\% IC 4.8-10.6 $\mathrm{p}<0.0001$ ) with a low probability for women to be hypocalcemic (OR 0.63, 95\% IC 0.4$0.8 \mathrm{p}=0.005)$.Conclusions - SARS-CoV-2 infection is associated with a higher prevalence of hypokalemia, hypocal- cemia, hypochloremia and sodium alterations. Hypokalemia is more frequent among women and hypocal- cemia among men. What is already known about this topic?Since SARS-CoV-2 spread, evidence regarding sex differences in progression and prognosis of COVID-19 have emerged. Besides, studies on patients' clinical characteristics have described electrolyte imbalances as one of the recurrent features of COVID-19. What does this article add? We observed a higher prevalence of hypokalemia in patients positive for SARS-CoV-2, and women were twice as likely to be affected than men. Positive patients also had a higher prevalence of hypocalcemia, hypochloremia and sodium alteration. Hypokalemia appears to be more frequent among women and hypocalcemia among men. INTRODUCTION Since December 2019 the world has been struggling to fight the novel coronavirus SARS-CoV-2. As soon as the virus spread in 
China, researchers noticed the higher predisposition of men to contract COVID-19 [1, 2]. Evidences emerged subsequently revealed also an association between male sex and a more severe disease and death [3, 4]. Some authors have attributed the reasons for these differences to sex differences in immune response [5], to differences in the prevalence of smoking subjects among men and women [6] and to genetics [7]. Few studies have investigated the impact of sex differences in clinical manifestations of the disease other than disease severity and mortality. Early studies on COVID-19 have highlighted the association between the disease and sodium $(\mathrm{Na}+)$, potassium $(\mathrm{K}+)$, calcium $(\mathrm{Ca}++)$ and chloride $(\mathrm{Cl}-)$ abnormalities $[1,8,9]$. Chen et al. [10] described a high prevalence of hypokalemic subjects among patients hospitalized with COVID-19. Furthermore, the severity of the disease was associated with a higher degree of hypokalemia. Authors have also shown, in a small sample of patients, that hypokalemic subjects had a higher mean urinary $\mathrm{K}+$ output than non-hypokalemic patients, suggesting a possible implication for increased $\mathrm{K}+$ urine loss. This mechanism could be explained by the disruption caused by the binding of SARS-CoV-2 to angiotensin-converting enzyme 2 (ACE2) with a possible impact on the renin-angiotensin system (RAS). Despite the aforementioned evidences, little is still known regarding electrolyte disturbances in COVID-19 and in SARS-CoV-2 infection. The aim of this study was to examine the prevalence of electrolyte imbalances among patients with SARS- CoV-2 infection in a large cohort and its distribution according to age and sex. Sex differences in electrolyte imbalances caused by SARS-CoV2: a case-control study METHODS The study protocol was approved by the Ethics Committee Area 3 Milano (prot. 92-15032020). Signed informed content was obtained for each participant. This study was conducted in accordance with the principles of the 1964 Declaration of Helsinki. Strengthening the Reporting of Observational Studies in Epidemiology (STROBE) reporting guidelines.DATA SOURCESThis case-control study has been performed at the ASST GOM Niguarda Hospital in Italy. At our hospital, we store all analytical results of the tests performed in the laboratory in an SQL-based repository. With the purpose to conduct this study, a query was created to extract data with no personal information other than gender and date of birth. This query extracted laboratory results based on the date of execution, the requesting department and the type of service performed. The fields extracted were: patient's ID (a numeric string that uniquely identifies the patient without personal data), sex, birth date day of lab tests execution (with a truncation for the extracted data referred to the period 1st March - 31st May), tests ID, tests results, hospital ward. In this way we were able to collect the biochemical and microbiological profile of patients at admittance to the emergency department (ED) and categorize patients based on their positivity (or negativity) to SARS-CoV-2, sex and age.STUDY PATIENTS AND COVARIATESWe considered a cohort of patients admitted to the ED from $1^{\text {st }}$ March to $31^{\text {st }}$ May 2020 and screened for SARS-CoV-2 infection. Inclusion criteria were: age over 18 years and the performance, during the per- manence in the Emergency Department, of at least one blood gas analysis (both arterial and venous) performed using POC Siemens RAPIDPoint 500 Blood Gas System. Compared to central Laboratory analyzers, results obtained from POC Siemens RAPIDPoint 500 blood gas system are stackable for all tested parameters taken into consideration in this study. These results are warranted for our own procedures and devices [11]. We collected data regarding electrolyte profile, $\mathrm{pH}$, blood glucose, white blood cell counts, lymphocyte counts, neutrophils, creatinine. We defined cases and controls according to the positivity or negativity to the nasopharyngeal swab test for SARS-CoV-2 by rtPCR (GeneFinder TMCOVID-19 Plus RealAmp Kit, ELITech; Allplex TM2019- nCoV Assay, Seegene) performed according to the World Health Organization (WHO) guidance. Positive patients were defined as cases and negatives as controls. Patients were then categorized in three classes according to age (under 65 years, between 65 and 75 years and over 75 years) and according to sex and age range combined into six groups: i) Females aged below 65 years; ii) Females aged between 65 and 75 years; iii) Females aged over 75 years; iv) Males aged below 65 years; v) Males aged between 65 and 75 years; vi) Males aged over 75 years.OUTCOMESAs outcomes, we considered potassium $(\mathrm{K}+)$, sodium $(\mathrm{Na}+)$, chloride $(\mathrm{Cl}-)$ and calcium $(\mathrm{Ca}++)$ both as continuous and as categorical variables, in their relationship with age, sex and SARS-CoV-2 infection status. We defined imbalances of $\mathrm{K}+, \mathrm{Na}+, \mathrm{Cl}-$ and $\mathrm{Ca}++$, according to ranges presented in Table 1. Leveraging the fact that a blood gas analysis was performed on the majority of patients accepted to the ED, we decided to consider the electrolyte values deriving from this analysis, to avoid potential bias due to the comparison of different methods. We analyzed potential effect modifiers such as renal disease, by calculating eGFR using the MDRD formula [12]. 
To get closer to precision medicine, it would be preferable to have all the information available in electronic form and the Human Phenotype Ontologies (HPO) is a useful tool for this purpose, making information available at different levels of granularity. The power of HPO has been demonstrated to enrich clinical data, including infectious diseases [13] and for this, to describe outcomes we use the terms of the "Human Phenotype Ontology" (HPO) to better promote the link between SARS-CoV2 to their phenotypes in support of infectious disease research. [Table 1 about here.]STATISTICAL ANALYSISPatients characteristics were summarized with mean and standard deviation for continuous variables and with number and percentages for categorical. Differences between the two cohorts have been tested with t-test and chi-square test, or Fisher exact test, respectively. Assumption of normality distribution was evaluated by Shapiro-Wilk test. A three-way ANOVA test was performed to evaluate differences among sex, class of age and presence of SARS-CoV-2 infection on potassium values. Tukey's multiple comparisons test was performed for post-hoc comparison. Several logistic regression analyses were performed to evaluate the relationship between SARSCoV-2 infection and electrolyte imbalances separately. Odds ratios (ORs) and confidence intervals 95\% (CI 95\%) were reported. Multivariable logistic regression considering SARS-CoV-2 positivity, age group and sex on hypokalemia, hypochloremia, hypocalcemia and abnormal natremia were performed. Odds ratios and CI $95 \%$ were reported. $\mathrm{P}$ values $<0.05$ were considered statistically significant. Sex differences in electrolyte imbalances caused by SARS-CoV2: a case-control study RESULTS For the retrospective cohort study of consecutive patients admitted to the ED from $1^{\text {st }}$ March 1 to $31^{\text {st }}$ May 2020 who had undergone blood gas analysis, 1347 patients were included. 710 (53\%) patients resulted positive to the nasopharyngeal swabs rtPCR test for SARS-CoV-2 and 619 resulted negative. Patients baseline characteristics between the two groups are summarized in table 2 . The case cohort was characterized by a lower prevalence of female subjects $(39 \%, 274 / 710)$, lower mean $\mathrm{pH}$ and lactate values $(7.23 \pm 0.37$ and $1.72 \pm 1.45 \mathrm{mEq} / \mathrm{l})$ and an electrolyte panel significantly different from controls for $\mathrm{K}+$ and $\mathrm{Ca}(3.80 \pm 0.49 \mathrm{vs} 4.11 \pm 0.62 \mathrm{mEq} / \mathrm{l}$ and $1.20 \pm 0.10$ vs $1.12 \pm 0.07 \mathrm{mEq} / \mathrm{l}$ respectively). Both cohorts were homogeneous for age, eGFR and renal disease prevalence. The prevalence of patients aged between 65 and 75 years was significantly higher in the SARS-CoV-2 positive cohort $(20.6 \%, 145)$, while there was a lower prevalence of patients aged under 75 years $(30.2 \%, 212)$. [Table 2 about here.]POTASSIUMWe analyzed the distribution of serum $\mathrm{K}+$ values as a continuous parameter with a three-way ANOVA on the basis of SARS-CoV-2 positivity or negativity, three classes of ages (years $>65 ; 65$ to $75 ;>75$ ) and sex. Results showed a clusterization (Figure 1) of serum $\mathrm{K}+$ values according to those parameters, and in particular to SARS-CoV-2 status. We then divided cases and controls cohorts according to their kalemic state (Table 3) and observed a higher prevalence of patients with hypokalemia in the group with SARS-CoV-2 infection. [Table 3 about here.] Further analyses of the population according to sex and class of age (Table 4) allowed us to observe a higher prevalence of hypokalemic patients among woman positive for SARS-CoV2. The prevalence was similar for all classes of age. The difference between positive and negative patients was statistically significant for men below 65 years $(\mathrm{p}=0.013)$, women below 65 years $(\mathrm{p}<0.001)$. In women over 75 years it was possible to note a difference which did not reach statistical significance $(\mathrm{p}=0.069)$. 


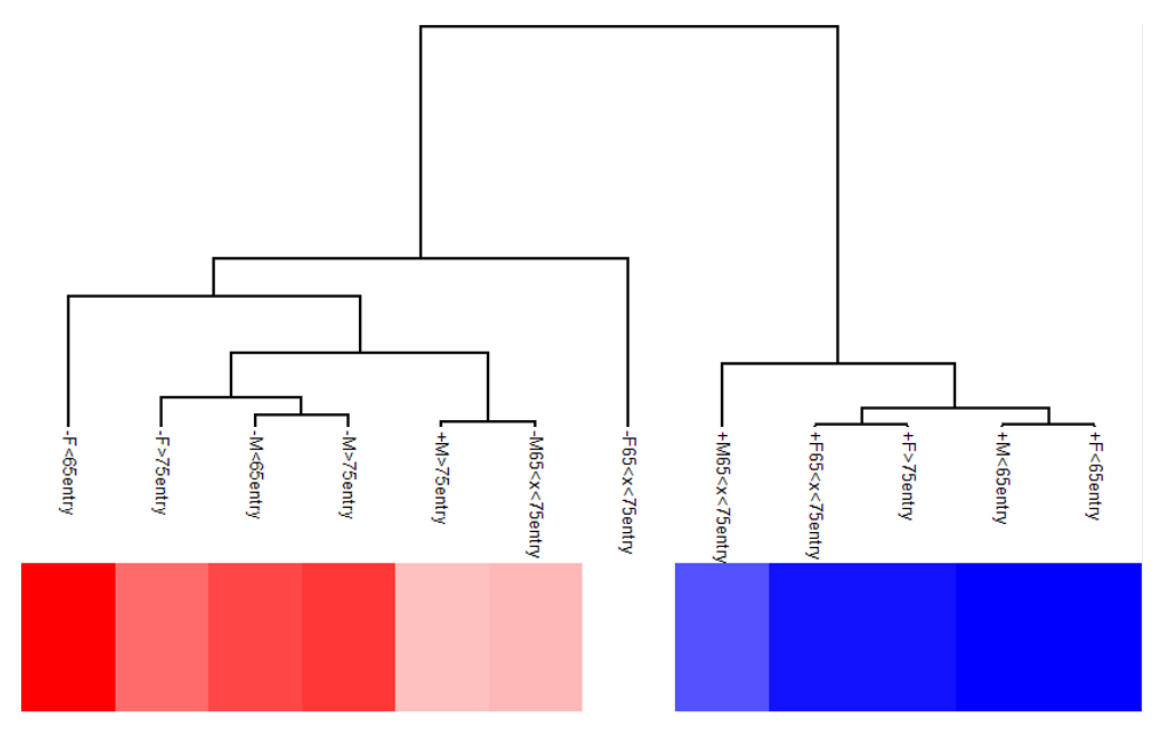

Figure 1. Heatmap of Post hoc Tukey's HDS test results. A Tukey's multiple comparisons test was performed to compare potassium between all groups. Euclidean distance and average linkage was used for clustering process. The test results were pre-processed using k-means before applying clustering and generating the heatmap and the dendogram. All test results were transformed for the analysis in Z-score intensity signal. Z score is constructed by taking the ratio of weighted mean difference and combined standard deviation according to Box and Tiao (1992). The application of a classical method of data normalization, z-score transformation, provides a way of standardizing data across a wide range of experiments. [Table 4 about here.] At binary logistic regression, the OR for patients with SARS-CoV-2 to present with hypokalemia at admission to the ED is twice than the one for non-infected patients (Table 5). At multivariable logistic regression, adjusting for age and sex, the probability to be admitted to the ED with hypokalemia was nearly three times higher for patients with SARS-CoV-2 infection (OR 2.75, 95\% CI 1.8-4.1 p <0.001) (Figure 2). For women, the probability to be admitted to the ED with hypokalemia, adjusting for SARS-CoV-2 positivity and age, is more than twice than the one for men (OR 2.43, 95\% CI 1.67-3.54 p $<0.001$ ) (Figure 2). [Table 5 about here.] Sex differences in electrolyte imbalances caused by SARS-CoV2: a case-control study 


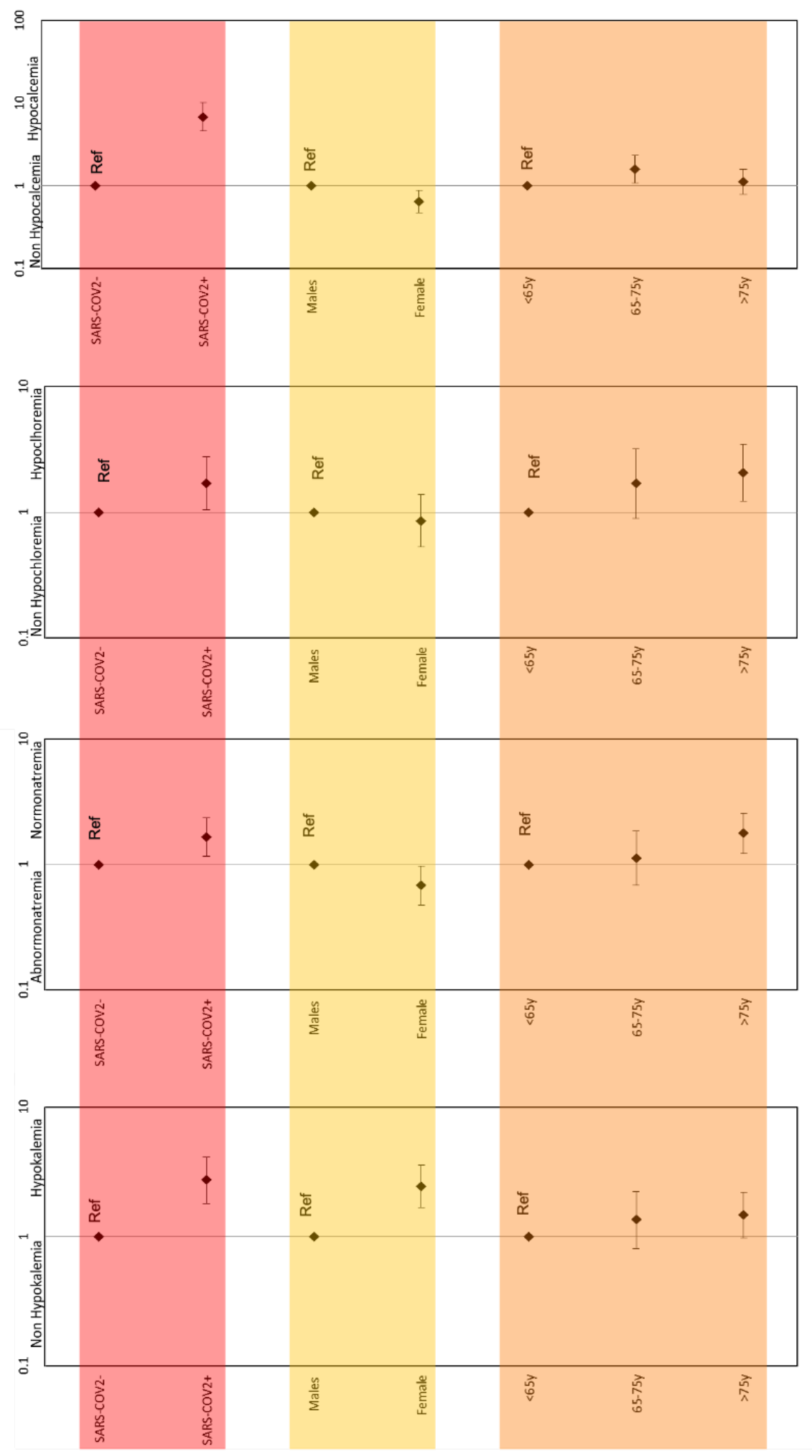

OTHER ELECTROLYTESRegarding natremia, we observed a higher prevalence of both patients with 
hyperrnatremia and hyponatremia among positive subjects (table a in Supplementary Materials). Women tended to be more hypernatremic while men were more hyponatremic. However, these differences among groups were not statistically significant (table b in Supplementary Materials). At logistic regression, patients with SARS-CoV-2 infection had a slightly higher probability to presents to the ER with an alteration in natremia (OR 1.6, 95\% CI 1.17-2.35 p<0.001). We detected also a mild tendency of infected patients to present with hypochloremia (table c Supple- mentary Materials) with no differences for sex and age groups (table d Supplementary Material). Lastly, nearly $30 \%$ of patients with SARS-CoV-2 infection presented to the ED with hypocalcemia versus $5.3 \%$ of negative subjects and only $0.4 \%$ were hypercalcemic among cases, compared to $7.4 \%$ of controls (table e Supplementary Materials). Differences among sex and age groups were visible with a lower prevalence of hypocalcemia among women compared to men, independently from infection status, and very significant differences between cases and controls for each of the six subgroups based on age group and sex. Prevalence of hypocalcemia among male patients with SARS-CoV-2 infection ranged from $28 \%$ to $34 \%$, compared to $16 \%$ to $32 \%$ of females (table $\mathrm{f}$ in Supplementary Materials). At binary logistic regression the OR for being hypocalcemic if positive to SARS-CoV-2 was 7.2 (95\% IC 4.8-10.6 $\mathrm{p}<0.0001$ ) and at multivariable logistic regression women had a lower probability to have hypocalcemia (OR 0.63, 95\% IC 0.4-0.8 $\mathrm{p}=0.005$ ) (Figure 2) DISCUSSION In this cohort study, we evaluated the association between electrolyte imbalances and SARS- CoV-2 infection, deepening its distribution according to age and sex. To our knowledge, this is the first study conducted on a very large sample describing electrolytes alterations in patients infected with SARS-CoV-2 at admission to the ED and compared with a similar cohort of non-infected patients. Differently from the results reported by Chen et al. [10], we observed a lower prevalence of hypokalemic patients and a lower severity of hypokalemia. This is because we considered not only patients hospitalized for COVID-19, but a population of subjects positive to SARS-CoV-2 with a highly heterogeneous grade of the disease. Moreover, the novelty of this study lies in the description of the important and significant differences observed among female and male patients. Among women, the difference in the prevalence of hypokalemic patients between cases and controls tended to decrease with increasing age. This could be an expression of a different hormonal influence between pre- and postmenopausal women. This is supported by the influence of female sex hormones, mainly estrogens, on ACE2 which are able to impact the ACE/ACE2 activity ratio and the expression of angiotensin 1-7 [14, 15], also according to age [16]. Regarding calcium we observed a reverse trend, with higher prevalence of hypocalcemia among male patients; a trend is also observed in the non-positive population, but exacerbated by SARS-CoV-2 infection. As reported elsewhere [17], sex differences in hypocalcemia could be correlated to the more frequent use of vitamin D and/or calcium among women for osteoporosis prevention [18]. From a pathophysiological perspective SARSCoV-2 is able to penetrate human cells by binding to ACE2 through a receptor binding domain present on the spike glycoprotein [19]. ACE2 is a receptor implied in the RAS system, in particular in the modulation of renal sodium transporters [20,21], especially the $\mathrm{Na}+/ \mathrm{K}+$ ATPase on the baso-lateral membrane of epithelial tubular cells [22, 23]. As explained in Figure 3, ACE2 cleaves angiotensin II in angiotensin 1-7, which is able to exert a natriuretic function by acting on the AT1 receptor. Furthemore, the action of ACE2 is also important to the vasodilation triggered by $\mathrm{Ca}++$ release from the endoplasmic reticulum induced by angiotensin 1-7. The disruption of this pathway caused by the binding of SARS-CoV-2 on ACE2 could underlie the electrolytes alterations observed in this study and others as well [1, 8-10]. Indeed, recent studies reported evidences of kidney damage manifesting as tubular dysfunction and necrosis, endothelial alterations and deposition of complement complex on tubules [24,25]. Electrolyte imbalances, especially of potassium and calcium, associated with SARS-CoV-2 infection could also help explain the numerous reports of QT prolongations, arrhythmias and cardiac deaths Sex differences in electrolyte imbalances caused by SARS-CoV2: a case-control study 


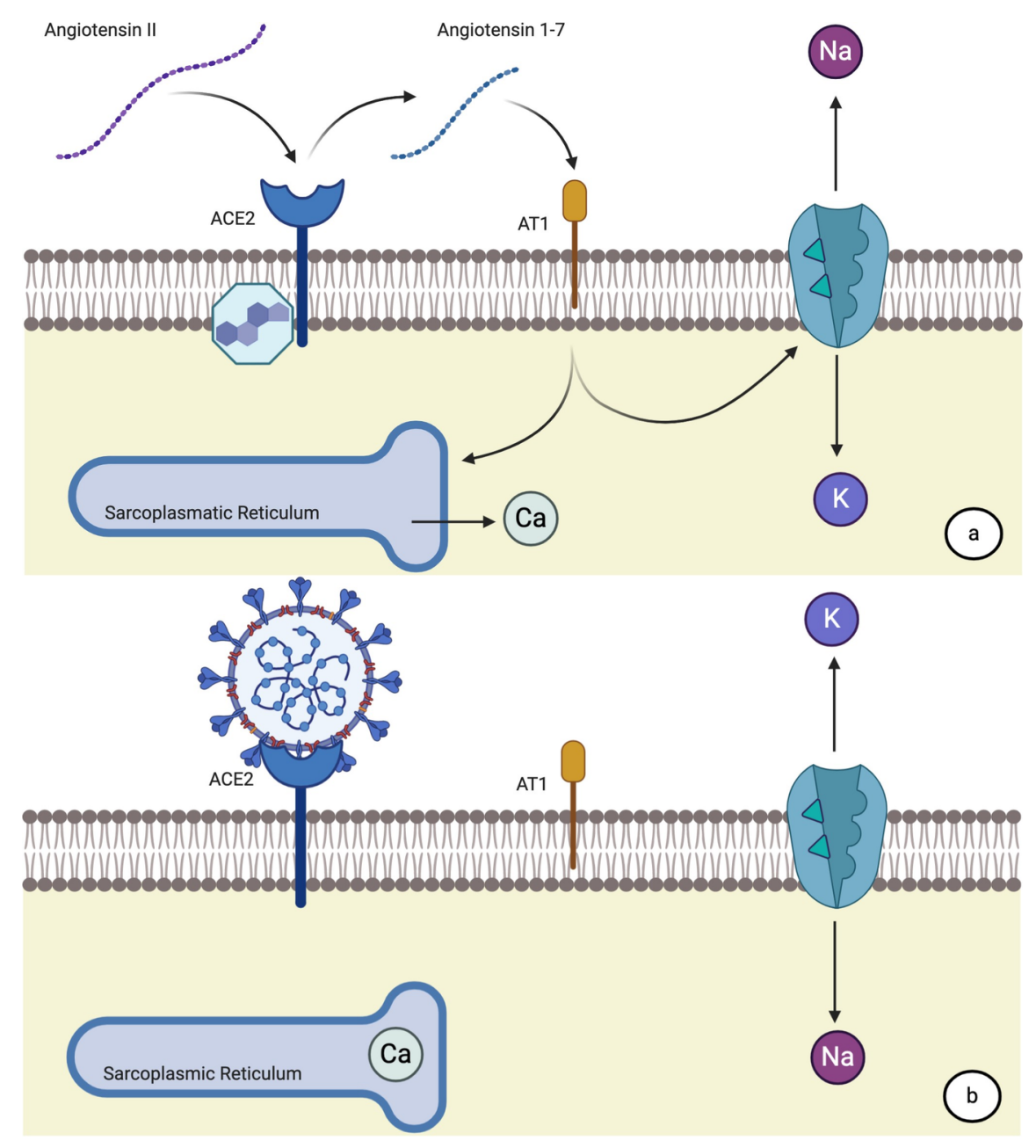

Figure 3. Actions of ACE2 on potassium, sodium and calcium imbalance and impact of SARS-CoV2 infection. Created with BioRender.com reported in patients with COVID-19 [26-28] and ascribed to treatments with macrolides and hydroxychloroquine [29,30]. This highlights the importance to continuosly monitor and manage hypokalemia and electrolytes imbalances [31,32] The limitations of this study lie in its retrospective nature and in the non-correlation of lab values with disease severity and clinical outcomes. Besides this, we believe that our findings are important to better understand the pathophysiology of COVID-19 disease, and especially sex differences in the manifestation of the disease which certainly impact on better prognosis for women. Clinical implications of this study are relevant from different perspectives. Monitoring kalemia, calcemia and electrolytes in general, is important in patients with COVID-19 and immediate supplementation should be suggested. The role of electrolytes imbalances should be further investigated also to understand the association with cardiovascular events reported in other studies.

\section{AUTHOR CONTRIBUTIONS}

A.P., E.I., F.S. contributed to study conception and design, data acquisition, analysis and interpretation, and paper drafting. V.C., C.A., A.B., contributed to data acquisition and analysis. V.A.F. contributed to study design and data acquisition. M.P., C.V., F.D.R., O.E., F.C., P.T., gave critical revision for intellectual content and contributed with patient enrollment and management. V.P., A.R., contributed to data analysis and interpretation, paper drafting, and gave critical revision. M.M., contributed to data interpretation, paper drafting, and gave critical revision for intellectual content. F.S. gave critical revision for intellectual 
content.

\section{TRANSPARENCY DECLARATION}

The manuscript is an honest, accurate, and transparent account of the study being reported; that no important aspects of the study have been omitted; and that any discrepancies from the study as planned (and, if relevant, registered) have been explained.

\section{FUNDINGS}

No fundings

Sex differences in electrolyte imbalances caused by SARS-CoV2: a case-control study LIST OF TABLES

1. Normality and abnormality ranges considered for electrolytes 12

2. Characteristics of study population 13

3. Study population distribution according to kalemia 14

4. Comparison between kalemia and SARS-CoV-2 infection according to age and sex........ 18

5. Univariable logistic regression of probability to develop hypokalemia for patients with SARS-CoV-2 infection 15

Table 1. Normality and abnormality ranges considered for electrolytes and relative HPO term

\begin{tabular}{llll}
\hline & Imbalance type & (HPO term) & Range \\
\hline Potassium $(\mathrm{K}+)$ & Hypokalemia & HP:0002900 & $<3.5 \mathrm{mmol} / \mathrm{l}$ \\
& Normokalemia & NOT HP:0011042 & $3.5-5.2 \mathrm{mmol} / \mathrm{l}$ \\
& Hyperkalemia & HP:0002153 & $>5.2 \mathrm{mmol} / \mathrm{l}$ \\
\multirow{5}{*}{ Sodium $(\mathrm{Na}+)$} & Hyponatremia & HP:0002902 & $<132 \mathrm{mmol} / 1$ \\
& Normonatremia & NOT HP:0010931 & $132-143 \mathrm{mmol} / 1$ \\
& Hypernatremia & HP:0003228 & $>143 \mathrm{mmol} / 1$ \\
Chloride $(\mathrm{Cl}-)$ & Hypochloremia & HP:0003113 & $<96 \mathrm{mmol} / 1$ \\
& Normochloremia & NOT HP:0011422 & $96-107 \mathrm{mmol} / 1$ \\
& Hyperchloremia & HP:0011423 & $>107 \mathrm{mmol} / 1$ \\
Calcium $(\mathrm{Ca}++)$ & Hypocalcemia & HP:0002901 & $<1.1 \mathrm{mmol} / 1$ \\
& Normocalcemia & NOT HP:0004363 & $1.1-1.4 \mathrm{mmol} / 1$ \\
& Hypercalcemia & HP:0003072 & $>1.4 \mathrm{mmol} / \mathrm{l}$ \\
\hline
\end{tabular}

Sex differences in electrolyte imbalances caused by SARS-CoV2: a case-control study Table 2. Characteristics of study population

\begin{tabular}{llll}
\hline & SARS-CoV2 - (619) & SARS-CoV2 & + \\
\hline & & $(710)$ & P value \\
Female (\%, n) & $48.2(297)$ & $39.0(274)$ & 0.001 \\
Age (mean, sd) & $61.9(21.15)$ & $63.7(16.2)$ & $<0.001$ \\
Class of age (\%, & & & \\
$\mathrm{n})$ & $50.0(308)$ & $50.3(353)$ & 0.002 \\
$<65$ years & $13.8(85)$ & $20.6(145)$ & \\
$65-75$ & $36.7(226)$ & $30.2(212)$ & $<0.001$ \\
$>75$ & $7.31(0.19)$ & $7.23(0.37)$ & 0.001 \\
pH (mean, sd) & $2.17(1.58)$ & $1.72(1.45)$ & 0.627 \\
Lactate, mEq $/ 1$ & & & \\
(mean, sd) & $10.30(9.38)$ & $8.08(6.01)$ &
\end{tabular}




\begin{tabular}{|c|c|c|c|c|}
\hline & SARS-CoV2 - (619) & SARS-CoV2 & + & $\mathrm{P}$ value \\
\hline Neutrophils & $7.10(4.00)$ & $5.98(4.02)$ & & 0.431 \\
\hline Haemoglobin & $14.03(2.23)$ & $13.93(1.92)$ & & 0.010 \\
\hline $\begin{array}{l}\text { Calcium, mEq/l } \\
\text { (mean, sd) }\end{array}$ & $1.20(0.10)$ & $1.12(0.07)$ & & $<0.001$ \\
\hline $\begin{array}{l}\text { Chloride, } \mathrm{mEq} / \mathrm{l} \\
\text { (mean, sd) }\end{array}$ & $102.86(4.28)$ & $101.62(4.17)$ & & 0.321 \\
\hline $\begin{array}{l}\text { Potassium, mEq } \\
\text { (mean, sd) }\end{array}$ & $4.11(0.62)$ & $3.80(0.49)$ & & $<0.001$ \\
\hline $\begin{array}{l}\text { Sodium, mEq/l } \\
\text { (mean, sd) }\end{array}$ & $137.43(4.36)$ & $135.84(4.50)$ & & 0.319 \\
\hline $\begin{array}{l}\text { Blood glucose, } \\
\mathrm{mg} / \mathrm{dl} \text { (mean, } \\
\mathrm{sd} \text { ) }\end{array}$ & $131.78(60.60)$ & $143.06(63.29)$ & & 0.275 \\
\hline $\begin{array}{l}\text { Creatinine, } \mathrm{mg} / \mathrm{dl} \\
\text { (mean, sd) }\end{array}$ & $1.11(0.63)$ & $1.15(0.96)$ & & 0.116 \\
\hline $\begin{array}{l}\text { eGFR, } \\
\mathrm{mL} / \mathrm{min} / 1.73 \mathrm{mq} \\
(\mathrm{mean}, \mathrm{sd})\end{array}$ & $74.06(44.10)$ & $74.36(44.41)$ & & 0.907 \\
\hline \multicolumn{5}{|l|}{$\begin{array}{l}\text { Renal Disease (\%, } \\
\text { n) }\end{array}$} \\
\hline eGFR $<90$ & $24.7(138)$ & $23.7(156)$ & & 0.227 \\
\hline $60<\mathrm{eGFR}<89$ & $4.5(243)$ & $49.0(323)$ & & \\
\hline $30<\mathrm{eGFR}<59$ & $25.8(144)$ & $20.8(137)$ & & \\
\hline $15<\mathrm{eGFR}<29$ & $4.7(26)$ & $4.7(31)$ & & \\
\hline $\mathrm{eGFR}<15$ & $1.4(8)$ & $1.8(12)$ & & \\
\hline
\end{tabular}

Table 3. Study population distribution according to kalemia

\begin{tabular}{llll}
\hline & SARS-CoV2 - (619) & $\begin{array}{l}\text { SARS-CoV2 }+ \\
(710)\end{array}$ & Total (1329) \\
\hline Hyperkalemia (n, \%) & $30(4.8)$ & $10(1.4)$ & $40(3.0)$ \\
Hypokalemia (n, \%) & $37(6.0)$ & $98(13.7)$ & $135(10.2)$ \\
Normokalemia (n, \%) & $552(89.2)$ & $602(84.8)$ & $1154(86.8)$ \\
\hline
\end{tabular}

Table 4. Comparison between kalemia and SARS-CoV2 infection according to age and sex.

\begin{tabular}{|c|c|c|c|c|c|c|c|c|}
\hline & & Hyperkalemia & Hyperkalemia & Hyperkalemia & Hyperkalemia & Hyperkalemia & Hyperkalemia & Hyperk \\
\hline & & $\begin{array}{l}\text { SARS-CoV2 - } \\
\mathrm{N}\end{array}$ & $\begin{array}{l}\text { SARS-CoV2 - } \\
\mathrm{N}\end{array}$ & $\begin{array}{l}\text { SARS-CoV2 - } \\
\%\end{array}$ & $\begin{array}{l}\text { SARS-CoV2 - } \\
\%\end{array}$ & $\begin{array}{l}\text { SARS-Cov2+ } \\
\mathrm{N}\end{array}$ & $\begin{array}{l}\text { SARS-Cov2+ } \\
\mathrm{N}\end{array}$ & $\begin{array}{l}\text { SARS- } \\
\%\end{array}$ \\
\hline$<65$ & $\mathrm{M}$ & 2 & 1.40 & 1.40 & 4 & 4 & 1.80 & 1.80 \\
\hline $65<x<75$ & $\mathrm{M}$ & 1 & 1.70 & 1.70 & 1 & 1 & 1.20 & 1.20 \\
\hline$>75$ & $\mathrm{M}$ & 2 & 1.70 & 1.70 & 2 & 2 & 1.70 & 1.70 \\
\hline$<65$ & $\mathrm{~F}$ & 19 & 11.80 & 11.80 & 1 & 1 & 0.80 & 0.80 \\
\hline $65<x<75$ & $\mathrm{~F}$ & 1 & 3.70 & 3.70 & 0 & 0 & 0.00 & 0.00 \\
\hline$>75$ & $\mathrm{~F}$ & 5 & 4.60 & 4.60 & 1 & 1 & 1.10 & 1.10 \\
\hline
\end{tabular}


Sex differences in electrolyte imbalances caused by SARS-CoV2: a case-control study Table 5. Univariable logistic regression of probability to develop hypokalemia for patients with SARS- CoV-2 infection Non Hypokalemia Hypokalemia OR CI 95\% p value

\begin{tabular}{llllllll}
\hline SARS-CoV-2 & $\begin{array}{l}n \\
612\end{array}$ & $\% 86.2$ & n 98 & $\% 13.0$ & 2.52 & $1.7-3.7$ & $<0.001$ \\
\hline $\begin{array}{l}\text { positive } \\
\begin{array}{l}\text { SARS-CoV-2 } \\
\text { negative }\end{array}\end{array}$ & 582 & 94.0 & 37 & 6.0 & 1 & & \\
\hline
\end{tabular}

1. Guan WJ, Ni ZY, Hu Y, Liang WH, Ou CQ, He JX, Liu L, Shan H, Lei CL, Hui DSC et al : Clinical Characteristics of Coronavirus Disease 2019 in China . N Engl J Med 2020,382 (18):1708-1720.

2. Yang X, Yu Y, Xu J, Shu H, Xia J, Liu H, Wu Y, Zhang L, Yu Z, Fang Met al : Clinical course and outcomes of critically ill patients with SARS-CoV-2 pneumonia in Wuhan, China: a singlecentered, retrospective, observational study . Lancet Respir Med 2020,8 (5):475-481.

3. Gebhard C, Regitz-Zagrosek V, Neuhauser HK, Morgan R, Klein SL:Impact of sex and gender on COVID-19 outcomes in Europe .Biol Sex Differ 2020, 11 (1):29.

4. Williamson EJ, Walker AJ, Bhaskaran K, Bacon S, Bates C, Morton CE, Curtis HJ, Mehrkar A, Evans $\mathrm{D}$, Inglesby $\mathrm{P}$ et al : Factors associated with COVID-19-related death using OpenSAFELY . Nature2020, $\mathbf{5 8 4}$ (7821):430-436.

5. Takahashi T, Ellingson MK, Wong P, Israelow B, Lucas C, Klein J, Silva J, Mao T, Oh JE, Tokuyama M et al : Sex differences in immune responses that underlie COVID-19 disease outcomes . Nature 2020, 588 (7837):315-320.

6. Paleiron N, Mayet A, Marbac V, Perisse A, Barazzutti H, Brocq FX, Janvier F, Bertrand D, Bylicki O: Impact of Tobacco Smoking on the risk of COVID-19.A large scale retrospective cohort study .Nicotine Tob Res 2021.

7. Asselta R, Paraboschi EM, Mantovani A, Duga S: ACE2 and TMPRSS2 variants and expression as candidates to sex and country differences in COVID-19 severity in Italy . Aging (Albany NY)2020, 12 (11):10087-10098.

8. Huang C, Wang Y, Li X, Ren L, Zhao J, Hu Y, Zhang L, Fan G, Xu J, Gu X et al : Clinical features of patients infected with 2019 novel coronavirus in Wuhan, China . Lancet 2020,395 (10223):497-506.

9. Qian GQ, Yang NB, Ding F, Ma AHY, Wang ZY, Shen YF, Shi CW, Lian X, Chu JG, Chen L et $a l$ : Epidemiologic and clinical characteristics of 91 hospitalized patients with COVID-19 in Zhejiang, China: a retrospective, multi-centre case series . QJM 2020,113 (7):474-481.

10. Chen D, Li X, Song Q, Hu C, Su F, Dai J, Ye Y, Huang J, Zhang X:Assessment of Hypokalemia and Clinical Characteristics in Patients With Coronavirus Disease 2019 in Wenzhou, China . JAMA Netw Open 2020, 3 (6):e2011122.

11. Allardet-Servent J, Lebsir M, Dubroca C, Fabrigoule M, Jordana S, Signouret T, Castanier M, Thomas G, Soundaravelou R, Lepidi A, Delapierre L, Penaranda G, Halfon P, Seghboyan JM. Point-of-Care Versus Central Laboratory Measurements of Hemoglobin, Hematocrit, Glucose, Bicarbonate and Electrolytes: A Prospective Observational Study in Critically Ill Patients . PLoS One . 2017 Jan 10;12 (1):e0169593.

12. Levey AS, Bosch JP, Lewis JB, Greene T, Rogers N, Roth D: A more accurate method to estimate glomerular filtration rate from serum creatinine: a new prediction equation. Modification of Diet in Renal Disease Study Group . Ann Intern Med 1999,130 (6):461-470. 
13. Kafkas, Ş., Abdelhakim, M., Hashish, Y. et al. PathoPhenoDB, linking human pathogens to their phenotypes in support of infectious disease research. Sci Data 6, 79 (2019)

14. Brosnihan KB, Neves LA, Joyner J, Averill DB, Chappell MC, Sarao R, Penninger J, Ferrario CM: Enhanced renal immunocytochemical expression of ANG-(1-7) and ACE2 during pregnancy . Hypertension 2003, 42 (4):749-753.

15. Brosnihan KB, Hodgin JB, Smithies O, Maeda N, Gallagher P:Tissue-specific regulation of ACE/ACE2 and AT1/AT2 receptor gene expression by oestrogen in apolipoprotein E/oestrogen receptor-alpha knock-out mice . Exp Physiol 2008, 93 (5):658-664.

16. Fernandez-Atucha A, Izagirre A, Fraile-Bermudez AB, Kortajarena M, Larrinaga G, Martinez-Lage $\mathrm{P}$, Echevarria E, Gil J: Sex differences in the aging pattern of renin-angiotensin system serum peptidases . Biol Sex Differ 2017, $8: 5$.

17. Catalano A, Chila D, Bellone F, Nicocia G, Martino G, Loddo I, Morabito N, Benvenga S, Loddo S: Incidence of hypocalcemia and hypercalcemia in hospitalized patients: Is it changing? J Clin Transl Endocrinol 2018, $13: 9-13$.

18. Catalano A, Morabito N, Basile G, Fusco S, Castagna G, Reitano F, Albanese RC, Lasco A: Fracture risk assessment in postmenopausal women referred to an Italian center for osteoporosis: a single day experience in Messina . Clin Cases Miner Bone Metab 2013,10 (3):191-194.

19. Shang J, Ye G, Shi K, Wan Y, Luo C, Aihara H, Geng Q, Auerbach A, Li F: Structural basis of receptor recognition by SARS-CoV-2 .Nature 2020, 581 (7807):221-224.

20. Santos RA, Campagnole-Santos MJ, Andrade SP:Angiotensin-(1-7): an update . Regul Pept 2000,91 (1-3):45-62.

21. Simoes-e-Silva AC, Baracho NC, Passaglio KT, Santos RA:Renal actions of angiotensin-(1-7) . Braz J Med Biol Res1997, 30 (4):503-513.

22. Caruso-Neves C, Lara LS, Rangel LB, Grossi AL, Lopes AG:Angiotensin-(1-7) modulates the ouabain-insensitive $\mathrm{Na}+$-ATPase activity from basolateral membrane of the proximal tubule .Biochim Biophys Acta 2000, 1467 (1):189-197.

23. Lara LS, Bica RB, Sena SL, Correa JS, Marques-Fernandes MF, Lopes AG, Caruso-Neves C: Angiotensin-(1-7) reverts the stimulatory effect of angiotensin II on the proximal tubule $\mathbf{N a}(+)$-ATPase activity via a A779-sensitive receptor . Regul Pept 2002,103 (1):17-22.

24. Maiese A, Manetti AC, La Russa R, Di Paolo M, Turillazzi E, Frati P, Fineschi V: Autopsy findings in COVID-19-related deaths: a literature review . Forensic Sci Med Pathol 2020.

25. Werion A, Belkhir L, Perrot M, Schmit G, Aydin S, Chen Z, Penaloza A, De Greef J, Yildiz H, Pothen $\mathrm{L}$ et al : SARS-CoV-2 causes a specific dysfunction of the kidney proximal tubule . Kidney Int 2020, 98 (5):1296-1307.

26. Chorin E, Wadhwani L, Magnani S, Dai M, Shulman E, Nadeau-Routhier C, Knotts R, Bar-Cohen R, Kogan E, Barbhaiya $\mathrm{C}$ et al : QT interval prolongation and torsade de pointes in patients with COVID-19 treated with hydroxychloroquine/azithromycin . Heart Rhythm 2020,17 (9):1425-1433.

27. Jankelson L, Karam G, Becker ML, Chinitz LA, Tsai MC: QT prolongation, torsades de pointes, and sudden death with short courses of chloroquine or hydroxychloroquine as used in COVID19: A systematic review . Heart Rhythm 2020, 17 (9):1472-1479.

28. Rosenberg ES, Dufort EM, Udo T, Wilberschied LA, Kumar J, Tesoriero J, Weinberg P, Kirkwood J, Muse A, DeHovitz J et al :Association of Treatment With Hydroxychloroquine or Azithromycin With In-Hospital Mortality in Patients With COVID-19 in New York State .JAMA 2020, 323 (24):2493-2502. 
29. Merino JL, Martinez-Cossiani M, Iniesta A, Escobar C, Rey JR, Castrejon-Castrejon S: COVID-19 and QT interval prolongation: more than just drug toxicity? Europace 2020,22 (10):1479.

30. Pani A, Lauriola M, Romandini A, Scaglione F: Macrolides and viral infections: focus on azithromycin in COVID-19 pathology .Int J Antimicrob Agents 2020, 56 (2):106053.

31. ESC guidance for diagnosis and manage- ment of cv disease during the covid-19 pandemic . 2020 .

32. Lauriola M, Pani A, Ippoliti G, Mortara A, Milighetti S, Mazen M, Perseghin G, Pastori D, Grosso P, Scaglione F: Effect of Combination Therapy of Hydroxychloroquine and Azithromycin on Mortality in Patients With COVID-19 . Clin Transl Sci 2020,13 (6):1071-1076. 